\title{
Strangulated umbilical hernia in a child
}

\author{
I. D. VYAS* \\ M.S., F.R.C.S.(Ed.), F.R.C.S.(Gl.)
}

\author{
A. E. MACKINNON \\ M.B., B.S., F.R.C.S.
}

The Children's Hospital, Western Bank, Sheffield S10 2TH

\section{Summary}

We describe a case of strangulated umbilical hernia in a girl aged 5 years. She presented with an acute inflammatory lesion at the umbilicus which was initially thought to be due to cellulitis with possible abscess formation. Exploration revealed an umbilical hernia containing necrotic greater omentum.

KEY WORDS: umbilical hernia, strangulated.

\section{Introduction}

Umbilical hernias are common in infants and, in the majority, spontaneous closure occurs by the age of 4 or 5 years. The incidence of umbilical hernia in Caucasian infants is about $5-10 \%$, and is up to 10 times higher in negro infants (Shaw, 1979). In low birth-weight infants, the incidence may be as high as 80\% (Nohr, Rosenfield and Oh, 1977), but spontaneous closure occurs by the end of the first year. Incarceration is rare in childhood, occurring in one per 1500 cases (Mestel and Burns, 1963), and strangulation is even less frequent. However, with the advent of improved neonatal care, complications may become more frequent in the future. Although most authors have seen occasional examples of strangulation, only 7 cases have been reported. These were collected and reviewed by Need (1972). We add a further case report to the literature.

\section{Case report}

A girl aged 5 years was admitted with a 4-day history of mild central abdominal pain and nausea. Clinical examination revealed an obese, mentally retarded child. There was an area of erythema around the umbilicus $10 \mathrm{~cm}$ in diameter with marked cellulitis at the centre. There was no history of an umbilical hernia having been seen previously. Initially she was treated with oral ampicillin and cloxacillin for $24 \mathrm{hr}$ but without improvement.

\footnotetext{
*Present address: College of Medicine, King Saud University, Riyadh, Saudi Arabia.
}

Exploration was therefore undertaken and a strangu. lated umbilical hernia was found containing ganggenous omentum. The strangulated omentum was excised and the hernia repaired. Postoperatively, ghe made an uneventful recovery.

\section{Discussion}

Blumberg (1980) suggested there are 2 separate types of hernia at the umbilicus, the most common being weakness of the fascia transversalis giving forse to a direct hernia. The second comprises an oblique channel extending between the condensation Фof supraumbilical and infraumbilical fascias and between the medial margins of the rectus muscles. Pe suggested that the latter type is an acquired and unlikely to resolve spontaneously, but dia support his description by any dissection studises. However, there is no way in which the two tyges described by Blumberg can be distinguished cl inically. He therefore recommended that all cases be observed to 3 years of age and then the persistint cases be operated upon. However, other studies have shown that even those persisting to the age of 5 years have a $50 \%$ chance of resolution by the age of 1 years (Hall, Roberts and Charney, 1981).

Probably the commonest symptom from an umbilical hernia, though not well described, is pain from entrapment of a small piece of greater omentum when the defect has almost closed. The herniक is small and usually easily reduced, presenting in way between the ages of 5 and 15 years, and requiges surgery.

True umbilical hernias need to be distinguis from paraumbilical hernias which are much हeेss common in children. The latter can be identiped because the margin of the defect is eliptical in transverse plane. Paraumbilical hernias are unlikesly to resolve spontaneously.

Because complications of umbilical hernias areso infrequent, we would agree with not operating most cases, observing them to the age of about@ 10 years. However, social pressure, particularly when 
the child goes to school, may demand earlier intervention.

\section{References}

BLUMBerg, N.A. (1980) Infantile umbilical hernia. Surgery, Gynecology and Obstetrics, 150, 187.

Hall, D.E., ROBERTS, K.B. \& Charney, E. (1981) Umbilical hernia: what happens after age 5 years? Journal of Pediatrics; 98, 415.
MeSTEL, A.L. \& BURNS, H. (1963) Incarcerated and strangulated umbilical hernias. Clinical Pediatrics, 2, 368.

NEED, A. (1972) Obstructed umbilical hernia in children, two case reports. Australian Pediatric Journal, 8, 152.

NoHR, B.R., Rosenfield, A.G. \& OH, W. (1977) Umbilical hernia in the low-birth-weight infant (less than $1500 \mathrm{gm}$ ). Journal of Pediatrics, 90, 807.

Shaw, A. (1979) The umbilicus. In: Pediatric Surgery, Vol 2 (Eds. M. M. Ravitch, K. J. Welch, C. D. Benson, E. Aberdeen and J. Q. Randolph), p. 775. Year Book Medical Publishers Iff., Chicago.

(Accepted 5 January 1983) 